\title{
Addressing occupational stress among health staff in non-government controlled Northern Syria: Supporting resilience in a dangerous workplace
}

\author{
Mahmood Othman*, Zachary Steel**, Catalina Lawsin***, Ruth Wells**, ****
}

\section{Key points of interest}

- Organisational strategies can reduce work stress even in situations of ongoing crisis and distress.

- A programme which focused on individual, team, organisational and contextual challenges to resilience in the workplace appears to have reduced some occupational stressors among health staff working in a conflict zone.

- More research is needed to understand the supra-organisational stresses that continue to contribute to work stress and innovative procedures are required to support grass roots organisations to communicate these to international funders. face the same challenges as the people they help. Supporting the wellbeing of these staff is crucial to the operation of health services for internally displaced Syrians given the large-scale destruction of healthcare infrastructure. Methods: Findings from a staffcare programme designed by a grassroots Syrian psychosocial organisation in Southern Turkey and implemented in a medical nongovernment organisation in Idlib in Northern Syria are presented. An iterative and collaborative process employed individual, team and organisational level consultation to identify occupational stresses within the workplace. A six-month programme involved group sessions across eight sites with 56 staff working in three primary health clinics, two mobile teams and one sexual and reproductive health clinic, serving eight internally displaced persons camps in Idlib. Results: Following the programme, staff reported significant reductions in role ambiguity, and improvements in the nature of their work, personal relationships with colleagues and superiors and physical conditions in the workplace. There were no significant differences in reported organisational structure or job satisfaction. Discussion: This evaluation of a grassroots programme, designed to address the expressed needs of displaced staff, suggests that reductions in daily living stresses can be achieved even in the context of ongoing crisis. 
Keywords: Torture, occupational stress, refugees, compassion fatigue, stress disorders, traumatic

\section{Introduction}

Syrian health workers in opposition controlled areas of Northern Syria provide care in situations of ongoing conflict, exposing them to enormous personal threat and danger. Organisational strategies are required to support these workers while they face the same stresses as the populations they serve. The results from a staff care programme conducted by a local NGO among national staff inside Northern Syria are presented. This programme operates across the levels of individual self-care, team cohesion and organisational structure to reduce organisational stresses and promote opportunities for social support with health staff working across eight sites in Northern Syria.

Recent research has demonstrated the systematic destruction of Syrian health care infrastructure in opposition controlled areas. Between November 2015 and December 2016, 938 people were injured by attacks against healthcare facilities, of which $24 \%$ were health care workers. Almost half of all hospitals were hit, a third multiple times (Elamein et al., 2017). Services providing trauma care in particular were subject to more frequent bombardment, supporting international allegations that aerial bombardment of health services is part of a systematic effort to undermine the capacity of oppositionheld areas to support military and civilian recovery from assault (Elamein et al., 2017). This is combined with reports of the widespread arrest, torture and murder of medical staff since 2011 (Heisler et al., 2015) which led to approximately $70 \%$ of medical staff leaving the country (Ben Taleb et al., 2015), undermining health services and leading to increases in communicable and non-communicable diseases (NCDs) (Abbara, Sahloul, Fouad, Coutts, \& Maziak, 2015). The use of torture has been a hallmark of Syrian regime tactics to silence opposition (Yassin-Kassab \& Al-Shami, 2016) and the collective punishment of opposition controlled areas may be considered a continuation of these policies, similar to the massacre of tens of thousands in Hama in 1982 (Van Dam, 2011).

Despite this, there remain a large number of Syrian medical practitioners and health professionals who continue to provide health care services directly in conflict-affected regions (Abbara et al., 2015) as well as in displacement settings. Research among displaced Syrians in Jordan has demonstrated a community desire among lay community members and health staff to contribute to the relief effort rather than just be recipients of international health aid (Wells, Wells, et al., 2016). The emphasis on participatory involvement and engagement is also consistent with a growing international discourse of global humanitarian intervention that challenges the traditional view of survivors of conflict as inevitably traumatised, passive recipients of aid (IASC, 2007), in favour of the generation of scalable interventions which incorporate local community members as active participants (WHO, 2010). Such an approach has the promise of large-scale, global public health benefits, with multiple studies demonstrating that lay staff can effectively deliver NCD and psycho-social mental health interventions (Lambert $\&$ Alhassoon, 2015). However, these programmes will only be sustainable if they ensure that the considerable stresses faced by these newly trained national staff are 
mitigated by staff care programmes which ensure that organisational structures meet their unique needs (Weine et al., 2002).

Local national staff, either in host communities or displaced communities, comprise a vital component of health system response to the crisis (Abbara et al., 2015), especially in low resource settings, yet current research tells us little about how to support their occupational and psychosocial needs. A 2016 scoping review of research into the mental health of humanitarian workers found that $60 \%$ of studies focused on psychosocial outcomes for expat workers from Western countries (Nordahl, 2016) despite the fact that over $92 \%$ of workers in humanitarian settings are national staff (Strohmeier \& Scholte, 2015). The predominance of national staff is even greater when security risks are high (Ager et al., 2012), as is the case in Northern Syria. Thus, extant research may not support the development of programmes for national staff (Lopes Cardozo et al., 2012) when research, for example, focuses on pre-, peri-, and post-deployment factors (Brooks et al., 2015), while host community staff are likely to remain in the setting, and displaced staff may never return home.

National staff face the dual challenges of working to support their communities, while also being subjected to the same extraordinary and continuous stresses (Eriksson et al., 2013). While some national health workers exhibit higher rates of posttraumatic stress disorder (PTSD) and depression than the local population (Strohmeier \& Scholte, 2015), others may find opportunities to learn new things about their personal capacities (Veronese, Pepe, \& Afana, 2016). Factors such as workrelated stress, overwork and burnout, and less time in the profession have been found to be more predictive of therapist distress than vicarious trauma among a sample of therapists working with trauma survivors in a high resource setting (Devilly, Wright, $\&$ Varker, 2009). Humanitarian workers reported that it was organisational structures which limited their capacity to help people (Nordahl, 2016) rather than exposure to traumatic material itself which caused significant distress. While an emerging body of international research into the wellbeing of humanitarian workers has examined factors at the individual level, few appear to have looked at the impact of organisational factors. For instance, in a review of 14 studies examining mental health outcomes among national staff in lower middleincome countries, only three looked at the impact of organisational structure on mental health. Two of these found that working for international non-governmental organisations (INGOs), as opposed to the UN, was associated with worse depression, indicating a key role of organisational policies in contributing to staff wellbeing (Strohmeier \& Scholte, 2015).

Measurement of community level and organisational factors may also be advised in conflict settings, as ongoing threat can preclude accurate measurement of individual mental health symptoms (Higson-Smith, 2013). International research into mental health consequences of conflict has tended to focus on PTSD and depression, finding rates of approximately 30\% (Steel, Chey, Marnane, Bryant, \& Ommeren, 2009). Symptoms associated with PTSD may be considered an adaptive survival response (Silove, 1998) in situations of real threat, so its measurement in ongoing conflict situations is likely to also capture distress and fear associated with the ongoing threat. In such a situation, current treatment models of PTSD may not be directly appropriate (Higson-Smith, 2013), as they are based on 
the assumption of the restoration of safety (Nickerson, Bryant, Silove, \& Steel, 2011). Since access to political rights may be central to wellbeing (Barber et al., 2014), alternative tools are needed to support the resilience of people who live and work in conflict situations. Taking steps to ensure that work settings are ones that promote health, rather than disappointment and stress may be an effective and economical way to do this. It can also have the added benefit of improving patient outcomes. For example, health workers who are more physically active are more likely to encourage physical activity with their patients, which is a low cost, drug-free way to improve both depression and PTSD symptoms (Rosenbaum et al., 2015), and prevent NCDs (Fie, Norman, \& While, 2012).

An ecological focus acknowledges that chronic stressors experienced in displacement are major determinants of distress (Miller \& Rasmussen, 2010), and may sometimes be experienced as more stressful than potentially traumatic events (Wells, Wells, et al., 2016), and are associated with mental health problems other than PTSD. For example, a study among national staff in Uganda found a greater prevalence of depression (68\%) than PTSD (26\%) resulting from chronic stressors such as financial problems (Ager et al., 2012). A focus on work-related stressors places the responsibility for change on organisations and the need for INGOs to focus on their role in supporting local staff (Eriksson et al., 2013). This paper aims to examine the impact of a six-month programme developed by an independent, Syrian staffed NGO to address organisational stressors and promote staff-care and opportunities for social support across eight sites in Northern Syria. Specifically, the question of whether the programme developed led to reduced organisational stressors is examined, including work nature, organisational structure, team relationships, job satisfaction, role ambiguity and physical conditions in the workplace.

\section{Methods}

Intervention Partners: Self-Care Provider Organisation

The self-care provider organisation was a grassroots psychosocial support organisation in Gaziantep in Turkey, $50 \mathrm{~km}$ north of the Syrian border. Staffed and run by Syrian psychiatrists, psychologists and other professionals, they take a capacity building approach to psychosocial support, mental health and psychotherapy. Supporting staff and organisations to build self-care skills is part of a broader programme which includes providing training, in specific skills to staff, as well as raising awareness at management level about organisational principles which can support health, and working together with the WHO to advocate for policy change. Self-care interventions aimed to: 1) Provide psychoeducation about workplace stress and increase community awareness; 2) Enhance self-care skills (e.g. through mindfulness); 3) Build team cohesion; 4) Analyse sources of pressure on teams and organisations; 5) Promote organisational activities to improve staff interactions; 6) Establish policies and guidelines for selfcare within the organisation in coordination with human resources.

\section{Participants}

Participants were 56 (20 female and 36 male) staff at pre-programme testing, and 52 (20 female and 32 male) at post-testing. All participants were of Syrian nationality aged between 18 and 50 years and had 
been working in the organisation between six months and over three years. The sample included both medical and support staff working for a medical international non-governmental organisation (INGO) in the North-Eastern region of Syria, in the Dana district of the Idlib governate, just east of the Turkish border. In June 2016, the district had a population of approximately 350,000 with 50,000 people being internally displaced persons (IDPs) (ACU, 2016). Staff worked across five primary health centres (PHCs) (three fixed clinics and two mobile teams) and one sexual and reproductive health clinic, across eight IDP camps (Qah; Al Douaa; Al Jolan; Al Salam; Al Nasser; Al Nour; Al Fourqan; Al Midan camps). Across the clinics, there were approximately 10,000 patient sessions per month, with individual doctors seeing 50 to 60 patients per day. Staff included medical staff (doctors, nurses, pharmacists, registrars) and operational staff (watchmen, drivers, administration, logisticians).

\section{Consent Procedures}

All participants gave informed consent prior to participating in the study. The nature and scope of the research project, lack of obligation to participate and absence of penalties for withdrawal, were explained prior to participants providing informed consent. Given that the research was conducted in a conflict zone without stable governance, ethical approval could not be sought from local authorities, a challenge that has been noted by other NGO organisations (Grandesso, Sanderson, Kruijt, Koene, \& Brown, 2005). Consistent with recommendations in the field (Grandesso et al., 2005; Van Griensven et al., 2006) ethical procedures for research were applied, in line with the declaration of Helsinki, involving prioritising the needs of participants over research design, de-identification and secure storage of data, and anonymous and voluntary data collection via online surveys to avoid perceived coercion.

\section{Measures}

Occupational stress questionnaire: The occupational stresses questionnaire (see Torture Journal website for a copy of the questionnaire) was developed as a self-report Arabic language tool to measure stress related to employment (Al-Otaibi \& Jaber, 2011). The 46-item scale has six dimensions:

1. Organisational structure: this includes organisational policies such as how employees are evaluated, what opportunities there are for reward and career growth opportunities;

2. Work nature: the degree of match between the expectations within a role and the individuals' capacities. This includes whether work is burdensome, overly complex or repetitious;

3. Physical conditions: assesses whether staff feel distressed by physical characteristics of the workplace on a daily basis, including temperature, ventilation, light, noise, cleanliness and order;

4. Relationships with colleagues and superiors: measures staff perceptions of their relationships both across and between hierarchical levels, degree of social support, level of cooperation or competition, tolerance and conflict;

5. Job satisfaction: assesses the staff member's sense of their own contribution within the workplace, whether they desire to leave their job, or desire career advancement within the organisation;

6. Role ambiguity: assesses the extent to which staff have sufficient information to fulfil their work roles including what kind of behaviour is expected of them 
and what their specific duties are. Items are answered on a five-point likert scale from 1 'a very small problem' to 5 'a very big problem.

In a sample of 122 administrative staff at Najran university in Saudi Arabia, all six dimensions showed predictive validity with significant negative correlations with internal locus of control $(r=-0.65)$ and time management skills $(r=-0.71)$. Subscales showed significant correlations with the total scale ranging from $r=0.52-0.78$ (Al-Otaibi \& Jaber, 2011).

\section{Procedure}

The programme was conducted by the self-care provider organisation. All of the staff were Syrian, including one supervisor operating in Turkey and three local Syrian facilitators running the sessions in Dana district, Syria. The aims of the programme were to raise awareness regarding the psychological effects of work stress, enhance self-care skills, improve team cohesion and understand the kinds of pressures staff face so that they can be addressed by management. See Figure 1 for programme components.

\section{Individual assessment: Questionnaires were} administered before the programme and again after six months. The programme focused on modifying the work environment and changing organisational attitudes to staff and self-care strategies. Thus, groups were run as open groups, with participants allowed to vary across sessions. The evaluations were undertaken anonymously so that it was not directly possible to link individual responses across the pre and post survey administrations. The initial stage involved administration of questionnaires to collect data about existing occupational stressors.
Collaborative agenda setting-focus groups: Three focus groups were conducted to identify needs and develop a focus for the programme. The self-care co-ordinator conducted the sessions, which included listening to current challenges as well as providing information about the possible structures for the programme. The notes from the groups were summarised and organised into the organisational levels, which included individual, team and organisational levels, as well as contextual factors affecting all levels. The first focus group included local management (i.e., staff managing local operations within Northern Syria rather than international management). Following this, the programme team agreed to undertake a needs assessment and then design a self-care programme tailored to the needs of staff. This included site visits to understand working conditions. The second focus group was with general staff. The project coordinator described the aims of the project and invited participants to discuss their needs relating to self-care. It was explained that the programme would focus on supporting staff to better manage their own stress rather than providing psychological therapy. The third session included management and involved feeding back results and generating an action plan.

Programme: Across a six-month period, staff attended a mixture of self-care sessions and organised activities. Sessions were run across the locations in an effort to reach as many staff as possible. Given the ongoing conflict and rapidly changing situation in the district, sessions could not always be run as scheduled. The same staff did not attend all sessions as movement of staff was often unpredictable, and the same staff may not have completed the pre and post questionnaires. Thus, occupational stress 
measured is indicative of overall stress at the group level, rather than individual changes in stress levels. Where possible, sessions were held every fortnight and two topics were covered per session. Staff were encouraged to identify their own self-care strategies and to practise them in their own time. See Table 1 for topics covered. While some topics aimed to help individuals to build their personal resilience (e.g. mindfulness, compassion meditation), others focused on supporting healthy relationships and social support among staff (e.g. nonviolent communication and gender-specific support groups). A female facilitator was provided to conduct the women's support group. Outdoor activities were planned together with staff to promote social support and provide opportunities for pleasant events. Feedback from the sessions was periodically provided to management who made subsequent changes to policy. For example, problems with the physical conditions in work spaces were raised with management, who subsequently addressed these issues.

\section{Statistical Analyses}

Demographic information for each group was analysed using chi-square analyses to test for differences between groups at preand post-programme. Given that individuals were allowed to vary across groups (i.e. participants were not necessarily the same at pre- and post-testing), this verified that the two groups had a similar composition. The individual items in the occupational stressors questionnaire were added up within each dimension and converted to an average score out of five per dimension. As scores were not normally distributed, each subscale was compared between preand post- groups using a one-sided, nonparametric Mann Whitney U test, Bonferroni corrected for six comparisons $(p=0.008)$. Item corrected correlations were calculated. Item discrimination was measured by dichotomising items $(\leq 2 ; \geq 3)$ and comparing proportions of endorsement between the upper and lower quartiles of both pre- and post- groups. Occupational stress scores were also compared between gender, age, profession and level of education using Mann Whitney U tests for two group analyses and Kruskal Wallis test for three group analyses.

\section{Results}

\section{Focus groups}

Focus group 1 was attended by five members of senior local management and the staffcare project co-coordinator. The organisation acknowledged the need for the provision of direct staff-care to both medical and logistical staff, as there was a lack of systematic and continuous psychological support for staff operating in these difficult to reach areas.

Focus group 2 was attended by 45 staff and three senior local management.

Participants discussed how the interaction of work and family pressures had negative impacts on their ability to work effectively and the administration of the clinics. Key issues raised are described below.

Contextual challenges:

- Everything that happens in the Syrian daily reality of pain was reflected in more pressures on daily living. There is no end in sight.

Individual challenges:

- Stress, tension and nervousness, difficulty managing emotions.

- Staff worrying about the people who depend on them, such as family and parents. 
Relationships with colleagues:

- Break down in relationships between colleagues (absence of love).

- Stress in fulfilling roles.

\section{Management issues:}

- Ineffective communication between local and international management.

- Lack of opportunities to be involved in decision making that effects their day to day work.

- Ineffective time management of clinics resulting in workload pressure.

- Lack of fairness in dealing with team members (discrimination).

- Focus on the form of work at the expense of the content of work.

Focus group 3 was attended by five senior local managers. An overall structure for the programme was agreed upon. Including: 1 ) Support sessions; 2) Recreational activities; 3) Team building. Self-care was to be implemented through three modalities with individuals, in group format, and liaising with management.

\section{Programme Design}

The programme components were designed in response to the challenges raised. Table 1 lists the topics covered. The first author used freely available online materials to design psychoeducation and practical strategies for each of the components. The contextual challenge of 'everything that happens in the Syrian daily reality of pain' was addressed through psychoeducation about moral injury and compassion fatigue to help participants understand and normalise possible emotional responses to witnessing injustice and suffering on a large scale. A range of individual self-care strategies were discussed and practiced to help people cope with the tension, nervousness, worry, stress and difficulty managing emotions raised in the focus groups. These included psychoeducation about the need for selfcare to prevent burnout and how to make a self-care plan. Self-care strategies included self-compassion, relaxation, sleep hygiene and mindfulness. All strategies were designed to help staff cope with stress and manage emotions, while acknowledging that they were continually exposed to ongoing stressors. Team focused components included non-violent communication, a method for developing skills for communicating one's needs to others and listening effectively. The group format facilitated the practising of techniques to improve communication between team members. In addition, a range of group activities were collaboratively devised to provide opportunities for social support and recreation. Organisational level strategies included regular feedback to management. A burnout prevention framework was presented which recommended policies such as: work plans that include rest periods; professional development opportunities; clarifying roles and responsibilities; staff input into procedure design; workload limits; giving detailed feedback at regular intervals; demonstrating how specific policies align with organisational values; providing training opportunities; ensuring regular contact with families; developing staff capacities. 
Figure 1: Diagram of study components

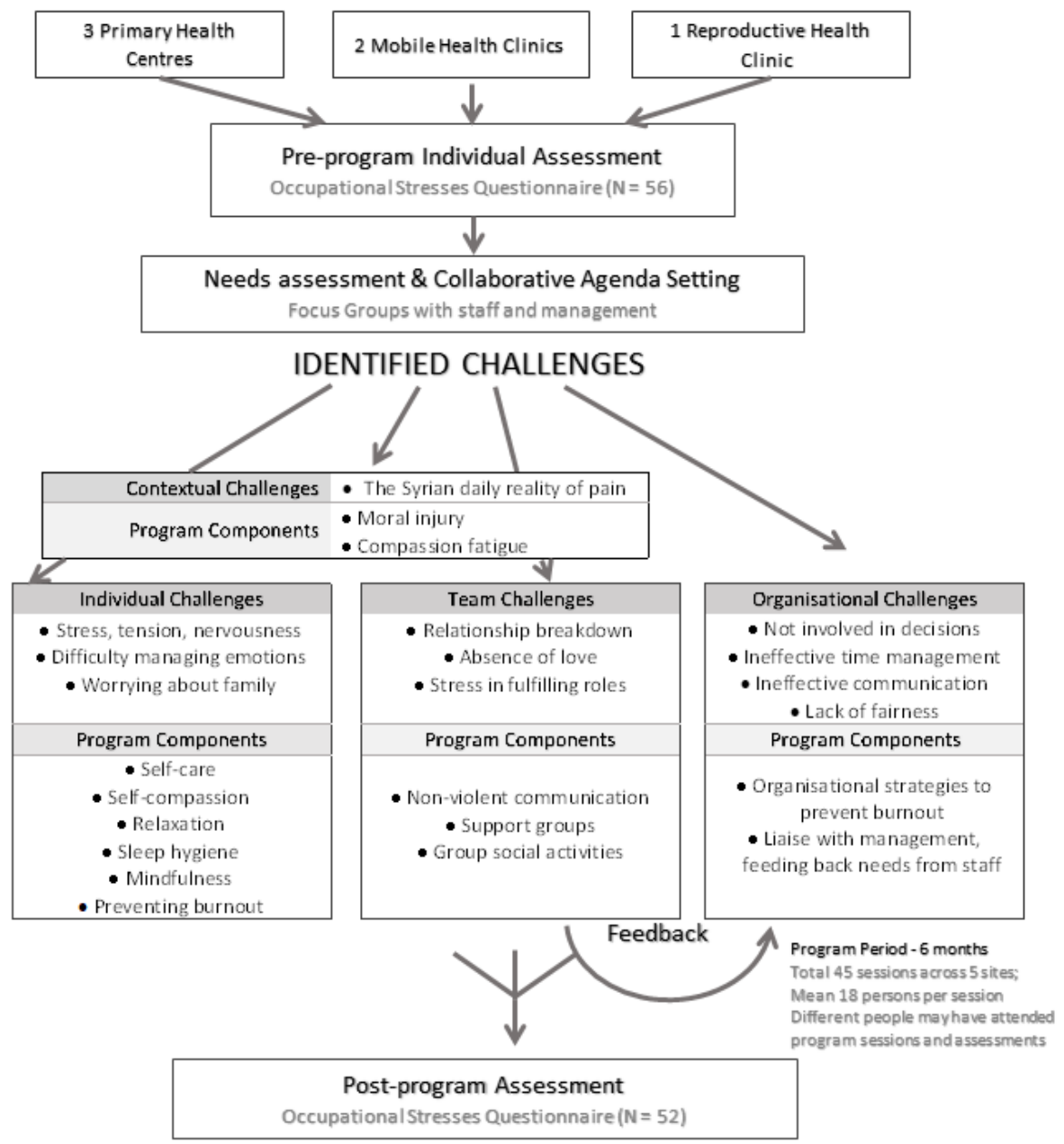

Note on Figure 1: Retentions rates are not shown as participants were not matched between groups during programme and at pre and post-assessment 
Table 1: List of topics covered in staff care programme

$\begin{array}{lll}\text { Topics Topic Content } & \begin{array}{l}\text { \# of } \\ \text { ses- } \\ \text { sions }\end{array}\end{array}$

Contextually Focused Programme components - To help with coping with 'the daily reality of pain' of living in Syria, with no end in sight.

\begin{tabular}{lll}
\hline $\begin{array}{l}\text { Moral in- } \\
\text { jury }\end{array}$ & $\begin{array}{l}\text { Psychoed: Moral Injury can occur in situations where all available options } \\
\text { violate one's personal values and beliefs. Associated guilt, shame and horror } \\
\text { can lead to PTSD. Witnessing injustice can change world view. } \\
\text { Strategies: Seek support, re-evaluate world view, speak to other survivors, re- } \\
\text { evaluate own culpability, make amends for perceived wrongs, address injustice } \\
\text { in the future. }\end{array}$ & 1 \\
& $\begin{array}{l}\text { Psychoed: Workers exposed to the intense suffering of others can develop ex- } \\
\text { Compas- } \\
\text { sion fatigue }\end{array}$ & 4 \\
& $\begin{array}{l}\text { Stration, low mood, anger, loss of interest in work, depersonalisation. } \\
\text { Sorkload, hobbient by regular supervision, good sleep and diet, exercise, reduce }\end{array}$ & \\
& work, take holidays, friends outside work, self-care.
\end{tabular}

Individually Focused Programme Components - To help individuals manage tension, nervousness, worry, stress and managing emotions.

Self-care Psychoed: Humanitarian workers are at increased risk of distress. Self-care can prevent disease and promote health. If you care for you own needs, you can better care for others.

Strategies: Make a plan for a range of activities including: Physical (exercise, diet, sleep); Emotional (have fun, mindfulness); Social (time with loved ones); Mental stimulation (new activity); and Spiritual (connect with values).

Self-com- Psychoed: Can help prevent compassion fatigue by helping caregivers focus passion on their own needs. Involves giving acceptance, empathy and non-judgement towards the self. Can help people who help others recognise their own physical and emotional needs.

Strategies: Be non-judgementally aware of your own pain, accept failures, refrain from self-criticism, focus on empathetically accepting your own needs without judging them.

Relaxation Psychoed: Relaxation can help you cope with living in a high-stress environtechniques ment close to conflict, worrying about people and dealing with others' trauma. Strategies: Diaphragmatic breathing, progressive muscle relaxation, mindful breathing.

Sleep Psychoed: Regular sleep can prevent burnout and compassion fatigue. Dis-

hygiene tress and stress can disrupt sleep, leading to further emotional problems. Strategies: Regular sleep schedule, don't exercise before bed, address worries, make sleep environment dark and comfortable, only use for sleep and sex.

Mindful- Psychoed: Can help you focus on the present moment instead of worrying moment. Describe what is happening, label your emotions without judging them, fully participate in an immersive experience. 


\begin{tabular}{llc}
\hline Topics & Topic Content & $\begin{array}{c}\text { \# of } \\
\text { ses- } \\
\text { sions }\end{array}$ \\
\hline Burnout & $\begin{array}{l}\text { Psychoed: A state of exhaustion, mental; physical; and emotional, which some } \\
\text { people experience after working in high-stress situations for long periods. } \\
\end{array}$ & 3 \\
& $\begin{array}{l}\text { Strategies: Social support; good sleep, diet, exercise, ensuring personal values } \\
\text { are in line with values and aims of organisation; ensure work nature matches } \\
\end{array}$ & your skills and interests, take regular breaks.
\end{tabular}

Team Focused Programme Components - To address relationship breakdown, absence of love and stress in fulfilling roles.

$\begin{array}{ll}\text { Nonviolent } & \text { Psychoed: Non-violent communication is a way to express personal feelings } \\ \text { communi- } & \text { and needs in a constructive and mindful way, while listening to the feelings } \\ \text { cation } & \text { and needs of others with empathy. } \\ & \text { Strategies: Develop awareness of own thoughts, feelings, and sensations. Use } \\ & \text { this awareness to communicate human feelings and needs with requests rather } \\ & \text { than demands. Compassionate appreciation of own and other's needs. Build } \\ & \text { partnerships based on shared values and goals. Assess outcomes by needs met } \\ & \text { and trust developed rather than right or wrong. }\end{array}$

Social Psychoed: Provide opportunities to build relationships, have fun together, lis-

Groups ten to each other, work towards shared goals.

Strategies: Separate women's and men's support groups. Outdoor activities: football for men, hair styling for women, lunch for all.

Note. 2 topics were covered in each session.

Questionnaire results: Table 2 presents the characteristics of the participants. Pre- and post-assessment is presented as a validity check in the absence of pre- postparticipant matching and some variation in the sample due to workplace changes over the study period. There were no significant differences between pre- and post- groups in age, gender, profession, marital status or education.

Participants in the pre-programme group reported a range of medical and non-medical professions. In the post group, participants reported their professions as either medical or non-medical. Half the participants in the post group reported receiving intermittent supervision (50\%), with 33\% reporting weekly supervision (see Supplementary Table S1). 80\% had previously received group self-care interventions in the past, yet only $6 \%$ had received individual psychological support for work-related issues.

\section{Occupational Stress}

The occupational stress scale showed high internal consistency in this sample for total scale (Cronbach's alpha $=0.974)$ and subscale scores (Occupational Structure $=0.87$; Work Nature $=0.865$; Physical Conditions $=0.844 ;$ Relationships $=$ 0.902; Job Satisfaction $=0.895$; Role Ambiguity $=0.913)$. Corrected item-total correlations were all above 0.35 while item discrimination was mostly above 0.3 in the pre-programme group, with three items showing discrimination below 0.17 . In the post-test group, six items showed zero discrimination due to a lack of endorsement in either quartile. 
Table 2: Demographics in pre- and post-programme groups

\begin{tabular}{|c|c|c|c|c|c|}
\hline & & $\begin{array}{l}\text { Pre } \\
\text { n (\%) }\end{array}$ & $\begin{array}{l}\text { Post } \\
\text { n (\%) }\end{array}$ & Chi Square & $p$ \\
\hline \multirow[t]{3}{*}{ Age } & $19-29$ & $21(38.5)$ & $22(42.3)$ & \multirow{3}{*}{0.59} & \multirow{3}{*}{0.744} \\
\hline & $30-39$ & $22(40.4)$ & $22(42.3)$ & & \\
\hline & $40-49$ & $11(21.2)$ & $8(15.4)$ & & \\
\hline \multirow[t]{2}{*}{ Gender } & Female & $20(35.7)$ & $20(38.5)$ & \multirow{2}{*}{0.09} & \multirow{2}{*}{0.768} \\
\hline & Male & $36(64.3)$ & $32(61.5)$ & & \\
\hline \multirow[t]{2}{*}{ Profession } & Medical & $35(63.6)$ & $39(75)$ & \multirow{2}{*}{1.62} & \multirow{2}{*}{0.203} \\
\hline & Non-Medical & $20(36.4)$ & $13(25)$ & & \\
\hline \multirow[t]{3}{*}{ Marital Status } & Married & $52(92.9)$ & $47(90.4)$ & \multirow{3}{*}{1.12} & \multirow{3}{*}{0.575} \\
\hline & Single & $2(3.6)$ & $4(7.7)$ & & \\
\hline & Widowed & $2(3.6)$ & $1(1.9)$ & & \\
\hline \multirow[t]{3}{*}{ Education } & School & $18(32.1)$ & $15(28.8)$ & \multirow{3}{*}{1.09} & \multirow{3}{*}{0.58} \\
\hline & University & $26(46.4)$ & $29(55.8)$ & & \\
\hline & Postgraduate & $12(21.4)$ & $8(15.4)$ & & \\
\hline
\end{tabular}

Note. Participants were not matched between pre and post.

Questionnaire results: Professional characteristics of pre and post groups

\begin{tabular}{llll}
\hline & & Pre (n) & Post (n) \\
\hline Profession & Admin & 16 & \\
& Doctor & 14 & \\
& guard & 3 & \\
& logistics & 1 & \\
& medical staff & 2 & \\
& midwife & 5 & \\
& nurse & 11 & 39 \\
& pharmacist & 3 & 13 \\
& Medical & & 9 \\
& Non-Medical & & 26 \\
Supervision & None & & 17 \\
& Intermittent & & 42 \\
Previous Self-care & Weekly & & 49 \\
Individual psychological support for work & No & 3
\end{tabular}


Table 3: Differences pre- and post-programme group differences in occupational stress

\begin{tabular}{|c|c|c|c|c|c|c|}
\hline Subscale & Group & Mean & SE & Median & $\begin{array}{l}\text { Mann Whit- } \\
\text { ney U }\end{array}$ & sig. \\
\hline \multirow{2}{*}{ Organisation } & Pre & 2.27 & 0.13 & 2.18 & \multirow{2}{*}{1070} & \multirow{2}{*}{0.085} \\
\hline & Post & 1.82 & 0.09 & 1.75 & & \\
\hline \multirow{2}{*}{ Job Satisfaction } & Pre & 1.89 & 0.11 & 1.63 & \multirow{2}{*}{1153.5} & \multirow{2}{*}{0.031} \\
\hline & Post & 1.59 & 0.09 & 1.37 & & \\
\hline \multirow{2}{*}{ Role Ambiguity } & Pre & 1.79 & 0.11 & 1.62 & \multirow{2}{*}{966.5} & \multirow{2}{*}{$0.001^{\star}$} \\
\hline & Post & 1.32 & 0.06 & 1.13 & & \\
\hline \multirow{2}{*}{ Work Nature } & Pre & 2.13 & 0.10 & 2.00 & \multirow{2}{*}{1040} & \multirow{2}{*}{$0.005^{\star}$} \\
\hline & Post & 1.75 & 0.09 & 1.62 & & \\
\hline \multirow{2}{*}{ Physical Conditions } & Pre & 2.04 & 0.10 & 1.88 & \multirow{2}{*}{906} & \multirow{2}{*}{$0.005^{\star}$} \\
\hline & Post & 1.59 & 0.09 & 1.5 & & \\
\hline \multirow{2}{*}{ Relationships } & Pre & 2.00 & 0.12 & 1.75 & \multirow{2}{*}{980.5} & \multirow{2}{*}{$0.0015^{\star}$} \\
\hline & Post & 1.46 & 0.07 & 1.25 & & \\
\hline
\end{tabular}

Note. Mann Whitney $U$ test compares distributions when those distributions are not identical, thus both Median and Mean are shown here for interpretation.

The Mann Whitney U test comparisons identified reductions in scores from pre- to post-programme assessments on all subscales. After correction for multiple comparisons, the domains of role ambiguity, work nature, physical conditions, and relationships showed significant differences, while organisation and job satisfaction did not reach significance (see Table 3). Figure 2 presents the median and interquartile range of the pre-post comparisons. There were no significant differences in age, gender, profession or level of education. See Table 4.

\section{Programme Retention and Adherence}

Staff self-reported whether they practised self-care strategies at home between sessions. Approximately $80 \%$ reported completing some kind of selfcare (e.g. mindfulness, exercise) during each month of the programme.

\section{Discussion}

The current study shows the results of a staff care programme conducted in a low resource, conflict setting. By focusing on organisational level change, this programme reduced sources of stress for Syrian health care staff who work in situations of ongoing threat. While such a programme cannot overcome the distress produced by conflict and displacement (Higson-Smith, 2013), it appeared to reduce occupational stressors known to be associated with burnout and depression, including role ambiguity, work nature, physical conditions in the workplace, and relationships with colleagues and management. The use of focus groups to understand staff needs and present these to management may have been a key factor in producing change. There have been recent calls for research into mental health for displaced people to focus more on the kinds of daily stressors that community members have identified as salient determinants of 
Figure 2: Distributions and medians of pre-and post-groups on the dimensions of the occupational stress questionnaire
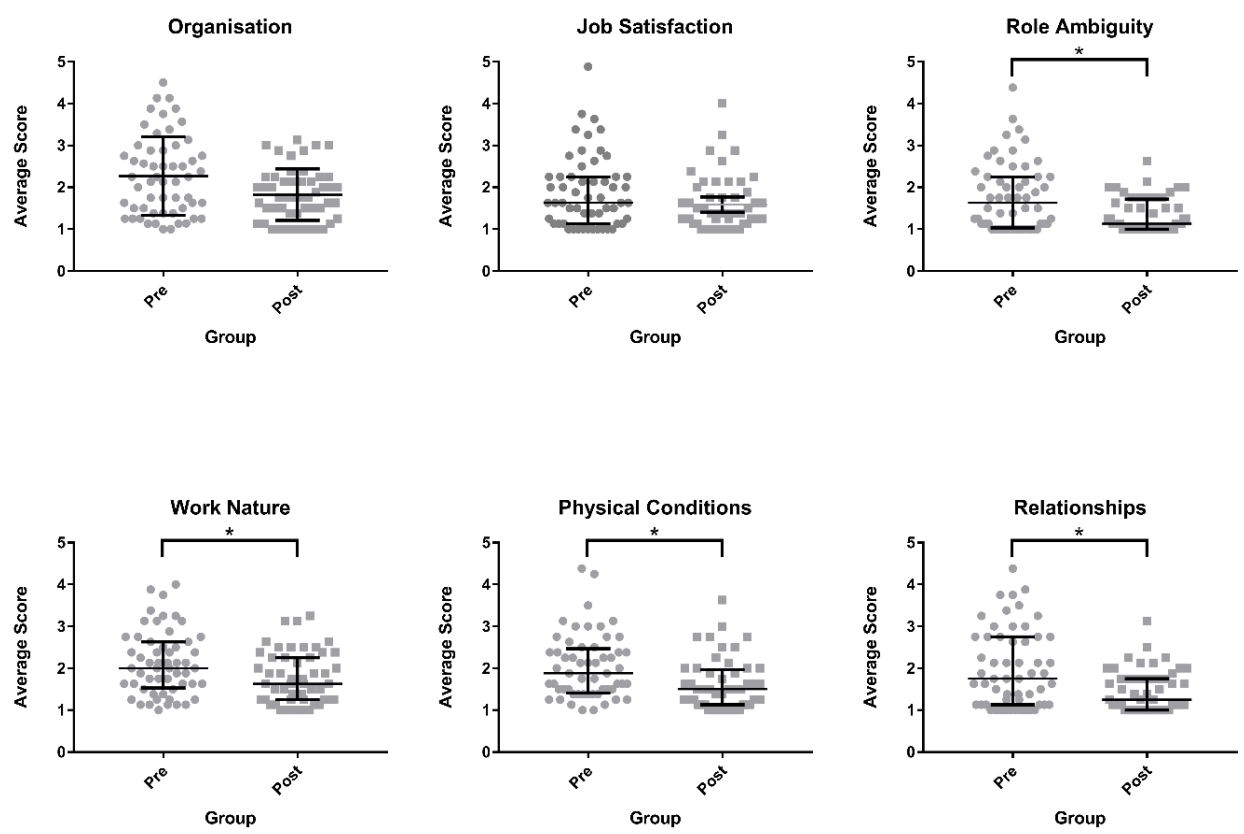

distress (Miller \& Rasmussen, 2010). This study responds to this and was designed and implemented by displaced Syrians working in Syria and Turkey. By measuring stressors rather than distress, the study avoids the methodological problems associated with measuring distress in contexts of conflict and displacement, where symptoms of PTSD are known to be elevated by situations of ongoing threat (Steel et al., 2006).

Humanitarian workers in other settings have reported that it is the combination of having a clearly defined occupational role and a close and supportive team environment which helps them to work effectively (Hearns \& Deeny, 2007). When work stressors combine, staff can experience burnout, a state of exhaustion, mental, physical, and emotional, which some people experience after working in high stress situations for long periods. Burnout is associated with health problems (Hamdan \& Hamra, 2017), and can lead to anxiety, depression and sleep disturbance, and can impact on patient care (Elbarazi, Loney, Yousef, \& Elias, 2017; Lopes Cardozo et al., 2012). People who experience burnout, are more likely to quit their jobs (Elbarazi et al., 2017; Hamdan \& Hamra, 2017). The findings of this study will be considered in the context of studies of burnout among humanitarian staff.

The significant reductions in reported role ambiguity in this study are notable in a crisis setting, as workers in such settings are often expected to take on expanded roles, amplifying role ambiguity (Nordahl, 2016). Given the rapidly changing situation and the limited number of health staff, staff 
Table 4: Group differences on occupational stress scores

\begin{tabular}{|c|c|c|c|c|c|c|c|}
\hline & & Pre & & & Post & & \\
\hline & & Median & $\begin{array}{l}\text { Mann } \\
\text { Whitney U/ } \\
\text { Kruskal-Wallis }\end{array}$ & $p$ & Median & $\begin{array}{l}\text { Mann } \\
\text { Whitney U/ } \\
\text { Kruskal-Wallis }\end{array}$ & $p$ \\
\hline \multirow[t]{3}{*}{ Age } & $19-29$ & 1.71 & \multirow{3}{*}{0.194} & \multirow{3}{*}{0.907} & 1.48 & \multirow{3}{*}{2.49} & \multirow{3}{*}{0.287} \\
\hline & $30-39$ & 2.06 & & & 1.58 & & \\
\hline & $40-49$ & 1.67 & & & 1.39 & & \\
\hline \multirow[t]{2}{*}{ Gender } & Female & 2.03 & \multirow{2}{*}{356.5} & \multirow{2}{*}{0.952} & 1.54 & \multirow{2}{*}{274.5} & \multirow{2}{*}{0.392} \\
\hline & Male & 2.05 & & & 1.42 & & \\
\hline \multirow[t]{2}{*}{ Profession } & Medical & 2.04 & \multirow{2}{*}{323.5} & \multirow{2}{*}{0.643} & 1.5 & \multirow{2}{*}{269} & \multirow{2}{*}{0.743} \\
\hline & Non-Medical & 1.98 & & & 1.42 & & \\
\hline \multirow[t]{3}{*}{ Education } & School & 1.78 & \multirow{3}{*}{0.49} & \multirow{3}{*}{0.783} & 1.48 & \multirow{3}{*}{0.798} & \multirow{3}{*}{0.671} \\
\hline & University & 2.06 & & & 1.52 & & \\
\hline & Postgraduate & 1.63 & & & 1.5 & & \\
\hline
\end{tabular}

Note. Mann Whitney U test used for two group tests, Kruskal Wallis test used for three group tests.

may be required to deal with issues beyond their experience or training (Abbara et al., 2015). Since there may be no opportunity to refer complex cases, working outside one's expertise may seem the only viable option. However, there is a need to ensure that organisations seek to place limits around staff responsibilities, by making clear what is, and is not, expected of them. There is an ethical obligation to balance patient need against staff wellbeing, in order to support staff to keep working. Strategies for clarifying roles were presented to management as part of this programme. It appears that this programme helped staff to clarify their understanding of their work responsibilities and what is expected of them, giving them more information to help them better achieve this ethical balance. The relevance of these findings to other low resource settings, in particular settings where task shifting is being employed to mobilise large numbers of newly trained health professionals, should also be highlighted. Recently trained staff, or staff not accustomed to working in humanitarian settings, may find being asked to perform functions they have not had sufficient training for particularly stressful (Eriksson et al., 2013). The vast majority of staff in this study had been in their roles for less than one year, yet research has demonstrated that lack of experience is a risk factor for burnout (Eriksson et al., 2013). In contrast, role clarity has been found to be protective among humanitarian staff (Brooks et al., 2015) and may enhance resilience.

This programme appears to have also impacted on the actual nature and burden of work. That is, staff reported less sense of being bothered by their responsibilities, 
being bored or overwhelmed by the number of duties and were less likely to report that they were exhausted by their work. Since work load has been associated with burnout in multiple studies, including in Arabic speaking countries (Elbarazi et al., 2017), this programme may have reduced risk for burnout. Easing the burden of work may also help staff to take advantage of opportunities to engage in healthy behaviours, as a systematic review of national humanitarian staff found those with lower workloads were more likely to engage in selfcare (Strohmeier \& Scholte, 2015).

Physical conditions in the workplace, such as excessive heat, cold or noise have been found to contribute to work stress among national staff in other conflict settings (Ager et al., 2012). Of note for staff in this study is the need to operate as a mobile team and in temporary accommodation, in a region that sees snow in winter and $40^{\circ} \mathrm{C}$ heat in summer. The significant improvements in physical conditions in this study reflects the iterative and consultative approach of this programme. The sessions generated a forum for such issues to be communicated to management in a constructive manner, which they then addressed.

The consultative approach may have also been key to the large improvements in perceived quality of relationships among staff and management. Social support among humanitarian workers has been associated with reduced burnout, depression and PTSD across a range of settings (Elbarazi et al., 2017; Eriksson et al., 2013; Hearns \& Deeny, 2007; Lopes Cardozo et al., 2012; Nordahl, 2016). Relationships among co-workers may help buffer wellbeing when protective organisational structures are lacking (Ager et al., 2012; Eriksson et al., 2013). Staff reported an increased sense that they were respected and encouraged by their managers, and a decreased perceived rigidity among their managers. The opportunity to collectively raise issues may have played a role in this. Staff also reported improved cooperation, tolerance and less conflict and competition among colleagues. There are multiple components of the programme that may have assisted in improving these relationships, including raising awareness about interpersonal sources of conflict, practising communication skills, participating in peer support groups and outdoor activities. In addition, raising awareness among management about the importance of encouraging supportive relationships may have also played a role.

While this programme was associated in reductions in problems with organisational structure and job satisfaction, these did not reach significance. Poor reward systems, perceived injustice and low job satisfaction (Elbarazi et al., 2017); poor management (Eriksson et al., 2013); lack of direction and recognition (Ager et al., 2012); and feeling you cannot really help people (Hearns \& Deeny, 2007) have all been associated with burnout. In particular, low salaries and lack of safety contribute to burnout (Lopes Cardozo et al., 2012), yet local workers are often paid less and provided with less security, health care and accommodation than expatriate staff (Eriksson et al., 2013). Given that concerns around fairness were raised in the needs assessment, future research should examine how to address problems of this nature.

Many factors associated with organisational structure and job satisfaction may have been out of the control of management to change. The first is the ongoing security situation; the second is the fact that management cannot control suffering and injustice in the community; thirdly, that organisational structures are 
often controlled by the external international humanitarian organisation which funds local projects, but which operates at a distance and is often unaware of the issues on the ground. This is consistent with the challenge raised in the needs assessment regarding communication between local and international management. More innovation is needed to promote constructive communication between local and international organisations which address extant power disparities. The fourth factor, an inherent problem in both crisis and low resource settings, is that there are often limited opportunities for career advancement in the absence of a larger health infrastructure. This may particularly be the case in task shifting paradigms where large numbers of lay staff are trained to complete circumscribed tasks, such as psychological first aid, or community health assessments. However, once these skills are mastered there may not be opportunities for advancement without tertiary academic qualifications, which may be geographically or financially prohibitive to obtain for those people who are living through a crisis. Thus, more senior positions tend to be occupied by expatriate staff.

We view this programme through an ecological framework which views social and psychological issues as operating within the nested systems of individual, group, community and society (Drozdek, 2015). This approach acknowledges that there are benefits and limits to intervention at any one level. Thus, individual interventions, such as health care or psychosocial treatment, operate within local organisations, which are nested within a certain cultural and political reality, and are influenced by international actors. In this programme, some people may have attended very few sessions, some people all, but it is hoped that the multiple layers of the intervention (individual, team, organisation) have led to changes in team relationships, work culture and organisational practices which result in the group difference observed. It may be that attendance at the sessions was not the only 'active ingredient' of the programme, which hopefully contributes to the sustainability of improvements.

\section{Limitations}

This project was conducted in a highly challenging situation. In addition, staff were under pressure to provide health care, so making time to attend sessions was sometimes difficult. The unstable security situation made regular provision of sessions across a scattered geographical area a challenge for staff and facilitators. In addition, a lack of familiarity with de-identification procedures commonly used in scientific research posed an additional challenge to data matching. While this is a common procedure taught in Western universities, staff from Syria may require support to implement this. Although it made theoretical sense to simply measure group level changes for an organisational programme, a within-subjects design would have allowed for considerably more power in analyses and may have contributed to the detection of differences for predictors of change. For example, there were no significant differences in gender, education, profession, age or time in role on the occupational stress scale. Some of this is in line with other research in occupational stressors, for example, the fact that gender differences were not significant (Maslach, Schaufeli, \& Leiter, 2001), yet some comparisons, such as between professions, may have reached significance in a withinsubjects design.

The Occupational Stresses questionnaire has not been validated in a sample of 
displaced people, a confirmatory factor analysis would have supported the validity of these findings. However, the sample size was not sufficient for this kind of analysis. The very high Cronbach's alphas observed also indicate possible redundancies among the questions, but sample size precluded an item response theory analysis. A lack of discrimination among individual items may also have indicated a floor effect. In addition, factors associated with the Syrian cultural context or the conflict context may have impacted on the validity of the scale. For example, staff may be prepared to accept less organised management or worse physical conditions when they understand that conflict limits access to resources. Alternatively, the context of threat may have made everyday problems, like poor physical conditions, more difficult to cope with because of heightened levels of distress. Future scales could include questions relating to the impact of the security situation or aspects unique to Syrian culture on work stress. Finally, it was not possible to arrange a control group, rather the study captured the impact across a whole organisation, taking advantage of an existing programme in a low resource setting, and it was not feasible to conduct assessments in a matched organisation.

\section{Conclusions}

Despite the considerable contextual challenges, this study suggests the potential for organisational programmes to reduce stressors for displaced health staff. The assessment process was embedded into programme design, with initial assessment being used to understand staff needs and begin an iterative, collaborative process. In particular, the programme was associated with improved staff relationships, clarified role ambiguity, improved physical conditions and staff's perceptions of the nature of their work. In light of current large-scale implementation of reskilling paradigms in health interventions in low resources settings, and the limited research on mental health outcomes for this group, care needs to be taken to ensure the wellbeing of staff. Such a programme may be scalable and cost-effective given that its impact may lead to increased retention and productivity among staff. Future programmes will need to focus on responding to local needs, promoting a bottom-up approach and providing opportunities for staff to be heard. This study suggests that improvements can be made, even when larger contextual challenges remain. Future research may examine the sustainability of these changes.

\section{Acknowledgments}

Particular thanks goes to Muhammad Kh. Shihadeh, Shevan Faysel Rasoul, Taha Muhammad Othman, and Abdullah Muhammad Zeydan.

\section{References}

Abbara, A., Sahloul, Z., Fouad, F., Coutts, A., \& Maziak, W. (2015). The Effect of the Conflict on Syria's Health System and Human Resources for Health. World Health \& Population, 16(1), 87-95.

ACU. (2016). Dynamo. Syria Dynamic Monitoring Report. . Retrieved from https://www.acu-sy.org/en/ syria-dynamic-monitoring-report-dynamo-v5/

Ager, A., Pasha, E., Yu, G., Duke, T., Eriksson, C., \& Cardozo, B. L. (2012). Stress, mental health, and burnout in national humanitarian aid workers in Gulu, northern Uganda. F Trauma Stress, 25(6), 713-720. doi: $10.1002 /$ jts. 21764

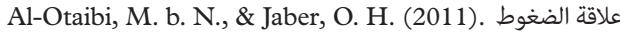
الوظيفية بالتوجه الشخصي لدى عينة من الإداريين بجامعة نجران (The relationship between occupational and personal stresses in a sample of administrators at the University of Najran). Fournal of Arab Studies in Education and Psychology, 21, 1432.

Barber, B. K., Spellings, C., McNeely, C., Page, P. D., Giacaman, R., Arafat, C., . . Mallouh, M. A. (2014). Politics drives human functioning, dignity, and quality of life. Soc Sci Med, 122, 90-102. doi:10.1016/j.socscimed.2014.09.055 
Ben Taleb, Z., Bahelah, R., Fouad, F. M., Coutts, A., Wilcox, M., \& Maziak, W. (2015). Syria: health in a country undergoing tragic transition. Int $\mathcal{F}$ Public Health, 60 Suppl 1, S63-72. doi:10.1007/ s00038-014-0586-2

Brooks, S. K., Dunn, R., Sage, C. A., Amlot, R., Greenberg, N., \& Rubin, G. J. (2015). Risk and resilience factors affecting the psychological wellbeing of individuals deployed in humanitarian relief roles after a disaster. $\mathcal{F}$ Ment Health, 24(6), 385-413. doi:10.3109/09638237.2015.1057334

Devilly, G. J., Wright, R., \& Varker, T. (2009). Vicarious trauma, secondary traumatic stress or simply burnout? Effect of trauma therapy on mental health professionals. Aust $N Z \mathcal{F}$ Psychiatry, 43(4), 373-385. doi:10.1080/00048670902721079

Drozdek, B. (2015). Challenges in treatment of posttraumatic stress disorder in refugees: towards integration of evidence-based treatments with contextual and culture-sensitive perspectives. Eur f Psychotraumatol, 6, 24750. doi:10.3402/ejpt. v6.24750

Elamein, M., Bower, H., Valderrama, C., Zedan, D., Rihawi, H., Almilaji, K., . . . AbouZeid, A. (2017). Attacks against health care in Syria, 2015-16: results from a real-time reporting tool. The Lancet. doi:10.1016/s01406736(17)31328-4

Elbarazi, I., Loney, T., Yousef, S., \& Elias, A. (2017). Prevalence of and factors associated with burnout among health care professionals in Arab countries: a systematic review. BMC Health Serv Res, 17(1), 491. doi:10.1186/s12913-017-2319-8

Eriksson, C. B., Lopes Cardozo, B., Ghitis, F., Sabin, M., Gotway Crawford, C., Zhu, J., . . Kaiser, R. (2013). Factors Associated With Adverse Mental Health Outcomes in Locally Recruited Aid Workers Assisting Iraqi Refugees in Jordan. Fournal of Aggression, Maltreatment E Trauma, 22(6), 660680. doi:10.1080/10926771.2013.803506

Fie, S., Norman, I. J., \& While, A. E. (2012). The relationship between physicians' and nurses' personal physical activity habits and their health-promotion practice: A systematic review. Health Education fournal, 72(1), 102-119. doi: $10.1177 / 0017896911430763$

Grandesso, F., Sanderson, F., Kruijt, J., Koene, T., \& Brown, V. (2005). Mortality and malnutrition among populations living in South Darfur, Sudan: results of 3 surveys, September 2004. fAMA, 293(12), 1490-1494. doi.org/10.1001/ jama.293.12.1490

Hamdan, M., \& Hamra, A. A. (2017). Burnout among workers in emergency Departments in Palestinian hospitals: prevalence and associ- ated factors. BMC Health Serv Res, 17(1), 407. doi:10.1186/s12913-017-2356-3

Hearns, A., \& Deeny, P. (2007). The value of support for aid workers in complex emergencies: a phenomenological study. Disaster Manag Response, 5(2), 28-35. doi:10.1016/j.dmr.2007.03.003

Higson-Smith, C. (2013). Counseling torture survivors in contexts of ongoing threat: Narratives from sub-Saharan Africa. Peace and Conflict: Fournal of Peace Psychology, 19(2), 164-179. doi:10.1037/a0032531

IASC. (2007). Interacgency Standing Committee Guidelines on Mental Health and Psychosocial Support in Emergency Settings.

Lambert, J. E., \& Alhassoon, O. M. (2015). Traumafocused therapy for refugees: meta-analytic findings. F Couns Psychol, 62(1), 28-37. doi:10.1037/ cou0000048

Lopes Cardozo, B., Gotway Crawford, C., Eriksson, C., Zhu, J., Sabin, M., Ager, A., . . Simon, W. (2012). Psychological distress, depression, anxiety, and burnout among international humanitarian aid workers: a longitudinal study. PLoS One, 7(9), e44948. doi:10.1371/journal.pone.0044948

Maslach, C., Schaufeli, W. B., \& Leiter, M. P. (2001). Job burnout. Annual review of psychology, 52(1), 397-422. doi.org/10.1146/annurev. psych.52.1.397

Miller, K. E., \& Rasmussen, A. (2010). War exposure, daily stressors, and mental health in conflict and post-conflict settings: bridging the divide between trauma-focused and psychosocial frameworks. Soc Sci Med, 70(1), 7-16. doi:10.1016/j.socscimed.2009.09.029

Nickerson, A., Bryant, R. A., Silove, D., \& Steel, Z. (2011). A critical review of psychological treatments of posttraumatic stress disorder in refugees. Clin Psychol Rev, 31(3), 399-417. doi:10.1016/j.cpr.2010.10.004

Nordahl, S. (2016). Mental health in and psychosocial support for humanitarian field workers. A Literature Review. (Masters), University of Oslo.

Rosenbaum, S., Vancampfort, D., Steel, Z., Newby, J., Ward, P. B., \& Stubbs, B. (2015). Physical activity in the treatment of Post-traumatic stress disorder: A systematic review and meta-analysis. Psychiatry Res, 230(2), 130-136. doi:10.1016/j. psychres.2015.10.017

Silove, D. (1998). Is Posttraumatic Stress Disorder an Overlearned Survival Response? An Evolutionary-Learning Hypothesis. Psychiatry, 61(2), 181190. doi:10.1080/00332747.1998.11024830

Steel, Z., Chey, T., Marnane, C., Bryant, R. A., \& Ommeren, M. V. (2009). Association of Torture and Other Potentially Traumatic Event with 
Mental Health Outcomes Among Populations Exposed to Mass Conflict and Displacement. A Systematic Review and Meta-analysis. Fournal of the American Medical Association, 302(5), 537549. doi.org/10.1001/jama.2009.1132

Steel, Z., Silove, D., Brooks, R., Momartin, S., Alzuhairi, B., \& Susljik, I. (2006). Impact of immigration detention and temporary protection on the mental health of refugees. The British fournal of Psychiatry, 188(1), 58-64. doi.org/10.1192/bjp. bp. 104.007864

Strohmeier, H., \& Scholte, W. F. (2015). Traumarelated mental health problems among national humanitarian staff: a systematic review of the literature. Eur F Psychotraumatol, 6, 28541. doi:10.3402/ejpt.v6.28541

Van Dam, N. (2011). The struggle for power in Syria: politics and society under Asad and the Ba'th Party: IB Tauris.

Van Griensven, F., Chakkraband, M. S., Thienkrua, W., Pengjuntr, W., Cardozo, B. L., Tantipiwatanaskul, P., . . . Gotway, C. (2006). Mental health problems among adults in tsunami-affected areas in southern Thailand. $\mathcal{F} A M A, 296(5), 537-548$. doi.org/10.1001/jama.296.5.537

Veronese, G., Pepe, A., \& Afana, A. (2016). Conceptualizing the well-being of helpers living and working in war-like conditions: A mixed-method approach. International Social Work, 59(6), 938952. doi: $10.1177 / 0020872814537855$

Weine, S., Danieli, Y., Silove, D., Ommeren, M. V., Fairbank, J. A., \& Saul, J. (2002). Guidelines for international training in mental health and psychosocial interventions for trauma exposed populations in clinical and community settings. Psychiatry: Interpersonal and Biological Processes, 65(2), 156-164. doi.org/10.1521/psyc.65.2.156.19936

Wells, R., Steel, Z., Abo-Hilal, M., Hassan, A. H., \& Lawsin, C. (2016). Psychosocial concerns reported by Syrian refugees living in Jordan: systematic review of unpublished needs assessments. Br F Psychiatry, 209(2), 99-106. doi:10.1192/bjp. bp. 115.165084

Wells, R., Wells, D., Steel, Z., Hunt, C., Alachkar, M., \& Lawsin, C. (2016). A Qualitative Study of Explanations of and Attitudes to Mental Health Concerns among Syrian Refugees Living in Jordan. In S. J. V. Bayardo (Ed.), Global Challenges and Cultural Psychiatry (Proceedings of the Puerto Vallarta World Congress) (pp. 165-176). Zapopan, Jalisco, México:Universidad de Guadalajara; Centro Universitario de Ciencias de la Salud; World Association of cultural Psychiatry and Grupo Latinoamericano de Estudios Transculturales: World Association of Cultural Psychiatry.
WHO. (2010). mhGAP intervention guide for mental, neurological and substance use disorders in non-specialized health settings: Mental Health Gap Action Programme ( $m h G A P)$.

Yassin-Kassab, R., \& Al-Shami, L. (2016). Burning Country: Syrians in Revolution and War: Pluto Press. London. 